\title{
BANDED VAULTS IN TURIN: TLS SURVEY, GEOMETRIC INTERPRETATION, DIGITAL RE-CONSTRUCTION, BETWEEN DESIGN AND CONSTRUCTION. PALAZZO CAPRIS DI CIGLIÈ
}

\author{
M. Vitali ${ }^{1}$, M. C. López González ${ }^{2}$, G. Bertola ${ }^{1}$, F. Natta ${ }^{1}$ \\ ${ }^{1}$ Dept. of Architecture and Design, Politecnico di Torino, Torino, Italy - (marco.vitali, giulia.bertola, fabrizio.natta)@polito.it \\ ${ }^{2}$ Dept. of Expresión Gráfica Arquitectónica, Universitat Politècnica de València, València, Spain - mlopezg@ega.upv.es)
}

KEY WORDS: Banded vaults, TLS, geometry, 3D Modeling.

\begin{abstract}
:
This contribution intends to focus attention on the banded vault ('a fascioni') that characterizes the atrium of the Capris di Cigliè Palace in Turin, whose construction is dated around 1730 and is attributed to Gian Giacomo Plantery (1680 - 1756).

The work of survey, analysis, interpretation and digital modeling has been organized in phases (detailed respectively in the next paragraphs) which have allowed us to: study the criteria of architectural-geometric composition at the base of the complex vaulted system that is the object of the present study and to relate them to the most usual operative practices of construction, in particular to the realization and arrangement of the centerings; organize the survey on the basis of the main treatise and manual sources, in order to choose the most appropriate working methods; analyze survey data and set up a parametric model of geometric interpretation; make a comparison between the survey data and the interpretive model.

In particular, the phases of geometric reading and interpretation, parametric modeling and discussion of the results were structured with the aim of studying in detail the different arches that define the structure of the banded vault.
\end{abstract}

\section{INTRODUCTION}

The present study is rooted in the broader research that, for about ten years now, is being conducted on complex vaulted systems, and that has seen the research group engaged in the analysis and study of the relationship between geometry, shape and design in the composition and construction of the atria of noble palaces within the historical fabric of Turin in the Baroque era (Spallone and Vitali, 2017). The research, directed by Roberta Spallone and Marco Vitali, is currently going on with the precious collaboration of Prof. Concepción López González (who joined the group thanks to the international collaboration project "Nuevas tecnologías para el análisis y conservación del patrimonio arquitectónico", funded by the Ministry of Science, Innovation and the University of Spain), the research fellows Giulia Bertola and Francesca Ronco and Fabrizio Natta, Ph.D. student.

The spaces of the palace dedicated to entrance and reception (atrium, secondary rooms and connection with the court of honor, the rustic court, the staircase, the hall and rooms connected to it on the main floor) participate in the definition of a fundamental design core, generally resolved with great compositional and scenographic unitary efforts, assuming a clear individuality in the structure of the palace. The atrium, and the rooms connected to it, therefore become fundamental elements on which to carry out surveying and digital reconstruction activities aimed, on the one hand, at establishing links and connections between design ideas and realizations and, on the other, at implementing a study methodology that allows, starting from the data of the laser scanner survey, to trace geometric-mathematical matrices of the characteristic sections of the built spaces (in particular the vaulted systems), to quantitatively evaluate the dimensional differences between designed architecture (ideal) and built architecture (real).

This contribution intends to focus attention on the banded vault (Lopez et al. 2020) ('a fascioni') that characterizes the atrium of the Capris di Cigliè Palace in Turin, whose construction is dated around
1730 and is attributed to Gian Giacomo Plantery (1680 - 1756). The palace was realized after the deep reshaping of the building fabric of the block "Santa Maria" in the historic city center.

From the distributive point of view, the representative spaces are articulated in hallway and atrium - covered respectively by a couple of small star-shaped vaults and a banded vault - and main staircase, scenographically linked to the atrium and disposed perpendicularly to the main facade. The atrium, set on a scheme of bands interrupted in the central field, seems to emphasize the axiality of the entrance path with the court of honor.

The atrium, rectangular in shape, has average dimensions of $9,33 \times 5,97 \mathrm{~m}$. and shows an impost height of 4,45 m. and height in key at $6,24 \mathrm{~m}$. The compositional scheme is set on a grid of $3 \times 3$ fields, in which two bands perpendicular to the major side divide the plan into three modules of comparable size. The bands perpendicular to the smaller side of the plan are flanked and interrupted at the central field (Fig. 1).

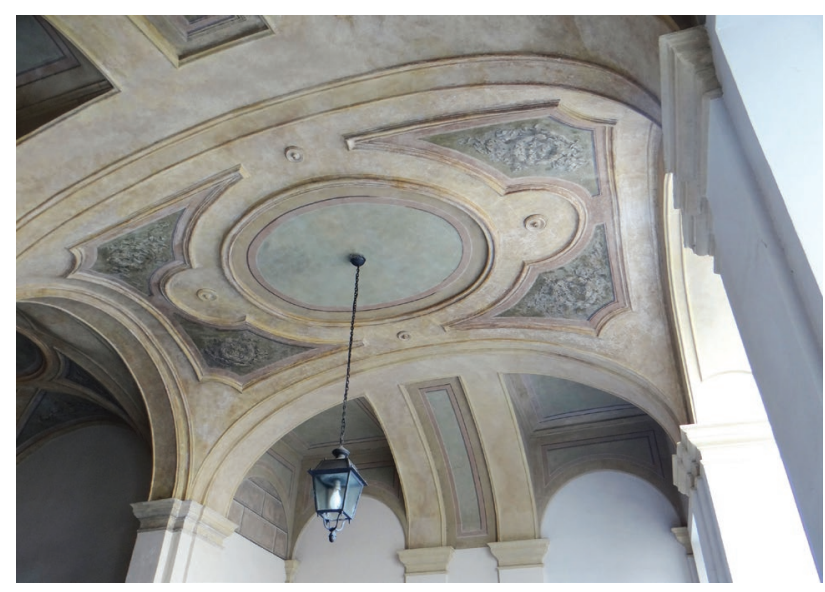

Figure 1. The main banded vault of the atrium of Capris di Ciglié Palace (photo by M. Vitali). 
The central field has a veloidic intrados, the surface of which has a continuous contact with arches and bands defining its perimeter, while the four corner fields are covered by lowered cloister vaults, with imposts above the bands.

The work of survey, analysis, interpretation and digital modeling has been organized in phases (detailed respectively in the next paragraphs) which have allowed us to:

- $\quad$ study the criteria of architectural-geometric composition at the base of the complex vaulted system that is the object of the present study and to relate them to the most usual operative practices of construction, in particular to the realization and arrangement of the centerings;

- $\quad$ organize the survey on the basis of the main treatise and manual sources, in order to choose the most appropriate working methods;

- $\quad$ analyze survey data and set up a parametric model of geometric interpretation;

- make a comparison between the survey data and the interpretive model.

In particular, the phases of geometric reading and interpretation, parametric modeling and discussion of the results were structured with the aim of studying in detail the different arches that define the structure of the banded vault (Vitali 2017).

\section{RELATIONS BETWEEN TREATISES, MANUALS AND CONSTRUCTION PRACTICES}

The analysis of architectural literature, treatises, and manuals, reveals the theoretical and applicative relations aspects established in the past between geometry, architecture, and construction.

Banded vaults, locally (in Piedmont) defined also 'a fascioni', are introduced, in treatises, by Guarino Guarini who, in the Architettura Civile (Guarini, 1737) for the first time makes a rigorous and meticulous examination of the vaulted systems, which is interwoven with aspects related to the invention, construction and calculation of surfaces and volumes also illustrated in the Euclides adauctus (Guarini, 1671) and in the Modo di misurare le fabriche (Guarini, 1674).

In the Treatise III of the Architettura civile, Capo Vigesimosesto, 'Delle Volte, e varj modi di farle', he dedicates the Osservazione Nona and the Osservazione Decima to the ' $a$ fascie' (banded) vaults, claiming their authorship. Regarding the spatial configuration, Guarini describes its genesis through a division of the room, «pulling from wall to wall, or into a frame, or by diagonal line various bands, which make themselves some compartments, and then the spaces that remain, I fill it of different Vaults according to the capacities of the field, that they leave [...] which they make very noble sight and leave fields dear for the painting»(1). In Plate XX of the Treatise III, an ' $a$ fascie' model is described in orthogonal projections (Fig. 2).

The systematic approach of Guarini opens the field to the experimentations and subsequent writings, which constitute a significant theoretical corpus both in relation to the refinement of the geometric description of the surfaces, and with regard to the description of the construction techniques and implementation of the vaults in masonry. In Italy, in fact, they will become the object of specific manuals only towards the end of the nineteenth century.

The 19th century studies on the vaults by Giovanni Curioni can also be used as a link between the theoretical and practical contributions. They are also favoured by scientific advances in the field of descriptive geometry and mathematics: by Giovanni

\footnotetext{
${ }^{1}$ Guarini, 1737, 189
}

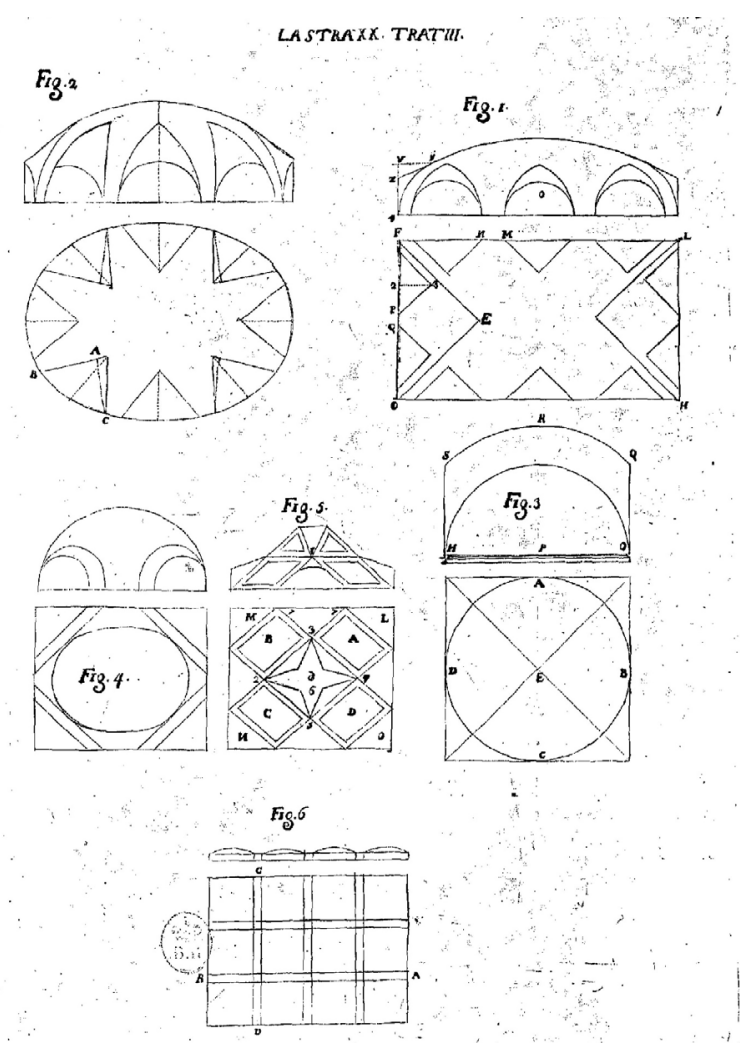

Figure 2. Guarino Guarini, Architettura civile (1737). Trattato III, Lastra XX. Volte 'a fascie' (fig. 4) e volte 'a fascie piane' (fig. 5)

Curioni we find numerous in-depth studies in various volumes of the work L'arte di Fabbricare, ossia corso completo di istituzioni teorico-pratiche per gl'ingegneri, per gli architetti, pei periti in costruzione e pei periti misuratori (in six volumes plus six appendices), oriented towards specific aspects of construction, from conception to installation.

In reference to the banded vaults, which Curioni calls ' $a$ fascioni', the individual volumes of the work offer useful indications.

In the Lavori generali (Curioni, 1866), with relation to the genesis of the banded vault, in analogy to what he illustrates in Geometria pratica, Curioni describes the system of arches that characterize it as the result of operations of section with vertical planes of a vaulted surface that covers the entire surface of the room: the surface «can be a barrel, an 'a conca', a cloister, a barrel with cloister heads, an ' a schifo', a dome»(2). The vertical planes, identified by lines on the impost plane, determine the subdivision of the vaulted surface in areas corresponding to 'arches' resting on the abutments and in mutual contrast with each other: in the spaces not covered by the arches the reference surface could be replaced by «appropriate vaults to which the beams serve as support together with the walls on which they lean»(3).

Accompanying the text, in Plate XXV, Curioni inserts the double orthogonal projection of a banded vault on a rectangular plan, in which the reference surface used is a cloister vault: the bands, disposed on the longitudinal and transversal axes, divide the vault into four sectors covered by others cloister vaults «having their impost planes above the highest points existing on the intrados of those arches»(4). In the same plate, Curioni shows the possible arrangement of the bands on an octagonal plan covered respectively by a sail and a cloister intrados surface (Fig. 3).

\footnotetext{
${ }^{2}$ Curioni, 1868, 288-291.

${ }^{3}$ Curioni, 1866, 368

${ }^{4}$ Ibid., 368
} 


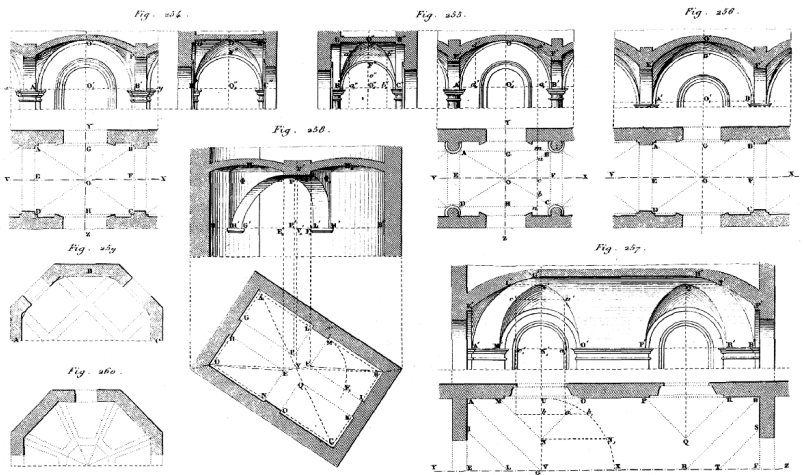

Figure 3. Giovanni Curioni, Lavori generali di architettura civile (1865), Plate XXV. Masonry structure of compound vaults.

In Article III, dedicated to the reinforcements, Curioni describes the construction of the centering for the banded vaults and prescribes the construction of two centering to define the course of the two extreme curves of each arch: these, «cut at the top so as to adapt to the limiting curves that these bands must show»(5) i.e. to the vertical sections of the reference surface, will be well connected to each other and firmly bound to the impost, while the intradossal surface of each band will be defined by a ruled surface that connects, through a planking, two contiguous sections.

In Geometria pratica (Curioni, 1868), in which the description of banded vaults follows that given in the Lavori generali, an approximate method of calculation is proposed for the intrados surface of the bands, replacing the surface of the arches by cylindrical surfaces. The calculation of the vaulted surfaces covering the fields into which the system is divided follows the methods proposed for each of the employable surfaces.

In Costruzioni civili, in Chapter 4, art. III, Vôlte, Curioni suggests the correct use for each type of vault and, with regard to the banded vaults, indicates that «they can be used to cover areas of a wide variety of shapes, but they are mainly used for those having a certain regularity»(6). In the part dedicated to stability testing, the subject of banded vaults is not discussed (Curioni, 1870).

Still within the local culture, Giovanni Chevalley, in his Elementi di tecnica dell'architettura: materiali da costruzione e grosse strutture, collected a summa of local constructive knowledge in the field of vaulted structures and enriched the cognitive framework through numerous tables in which he indicated the most usual brick equipment, the arrangement of the centering and the development of the intrados surfaces (Chevalley, 1924).

In the description of the 'a fascioni' vaults, which he puts together with the ribbed vaults, since in both cases the vaulted system is born from the combination of arches and vaults, Chevalley proposes a categorization in two variants: a first type of fascioni vault «consisting of simple or compound vaults from the surfaces of which the bands protrude: these can be arranged parallel to each other or even cross each other»(7), and a second, more complex and more adherent to the compositional schemes proposed by Guarini and Curioni, in which the room to be covered can be divided into fields through the construction of arches «and each of the resulting fields covered by secondary vaults»(8). In the description Chevalley indicates some built examples, emphasizing their spatial qualities, and recall a wide

\footnotetext{
${ }^{5}$ Ibid., 379

${ }^{6}$ Curioni, 1870, 188.

${ }^{7}$ Chevalley, 1924, 268.

${ }^{8}$ Ibid., 270.
}

use of these vaults in Baroque architecture, especially for large rooms, such as atriuma and halls of palaces.

In this context, in Guarini's and Curioni's texts, two different approaches to the geometric genesis of banded vaults emerged: Guarini's approach suggests the genesis of banded vaults starting from the 'independent' surfaces that define the shape of the arches that divide the vault: in this sense the arches are thought of as autonomous surfaces with precise characteristics, ascribable to geometrical primitives: the cylinder, the cone, etc...; in Curioni's and Chevalley's approach the arches depend on a reference surface, often a surface with double curvature (such as the 'a conca' surface), and in this sense they can be defined as 'dependent' arches (Spallone and Vitali, 2017).

As will be seen in the next paragraphs, the case study examined presents both types of surfaces, dependent and independent, in a configuration that puts together and hierarchizes them.

\section{LASER SCANNER SURVEY}

The study of complex surfaces, such as those developed in the vaults of the atriums of the Turin Baroque palaces, can only be approached through the elaboration of a rigorous planimetry because it is the most effective tool for the knowledge and analysis of architectural heritage (Almagro, 2019). The intrados image of these vaults reveals a great complexity of shapes whose geometric interpretation requires an extraordinarily rigorous planimetry. Therefore, data collection cannot be approached by traditional methods because the results would only refer to a series of discretionary points that do not reproduce the entire intrados surface. Fortunately, in recent times, technological renewal has advanced greatly. Photogrammetry and lasergrammetry have enabled the generation of 'digital twins' (Auer Ram, 2019) that contribute to the actual graphical representation of complicated features.

For the massive data capture aimed at the digitization and geometric analysis of the surfaces that make up the complex Turin Baroque vaults, the 3D laser scanning technique has been selected. The result obtained with photogrammetric methods depends directly on the technical quality of the photographic images (Stanco, Battiato, Gallo, 2017). However, the 3D scanner is not subject to this dependence. Moreover, the processing of point clouds is becoming more and more efficient shortening the time needed to register the clouds in a single reference system. The Faro Focus 3D x 130 HDR scanner was used. Its small size and light weight $(5.2 \mathrm{~kg})$ make it easy to transport to buildings located on roads where road traffic is restricted. To these characteristics must be added the speed and precision of the laser units, the high density of points, the HDR images of the associated cameras that provide real-looking multicolored clouds and the low error (2 mm every $25 \mathrm{~m})$ (Morena et al., 2020) (Fig. 4).

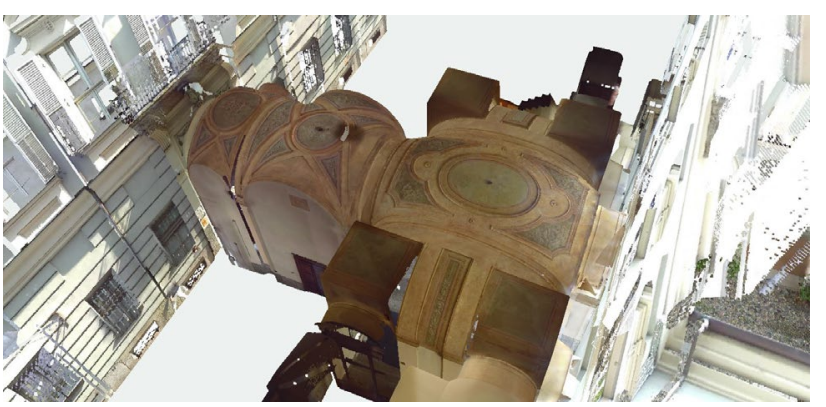

Figure 4. Point cloud of the vaulted system of the Capris di Cigliè palace. The HDR of the cameras attached to the Focus $3 \mathrm{D} \times 130$ scanner provides colours close to reality (processing by C. López González). 
This last feature allows discriminating deformations suffered in the vaults, both due to settlement during their construction and to other circumstances that occurred during their life. It is precisely these graphic results that allow the comparative geometric analysis between the real architecture and the original model.

In the atrium of the Capris di Cigliè Palace there is a succession of well-differentiated but perfectly interconnected spaces, forming a unitary core of design that acquires its own personality. The compositional design is reinforced by banded vaults that contribute very effectively to the creation of a scenography marked by the reticular decomposition of space without losing the theatricality of a place so important in the ceremonial use of the palace. This structuring of the space represents the starting point on which to plan the sequence of the scanner location points.

Before starting the scanning, the stations were programmed taking into account two essential parameters for optimal results: the maximum reduction of blind spots that prevent the verification of all the points that make up the vaulted surfaces and the dividing arches; and the adequate overlapping between scans to ensure reliable results in the recording of the point clouds. To satisfy the first condition, the scanning stations were positioned under each of the vaults that make up the intrados surface. In this way, all the points that make up the concave surface of each of the partial vaults are recorded and, at the same time, the blind spots formed by the ornamental moldings that circumscribe them are minimized. Adequate overlapping of the scans is guaranteed by maintaining a distance between stations of 6 to $15 \mathrm{~m}$., which could be reduced if the geometric characteristics make it advisable. This ensures reliable results and greatly reduces subsequent problems that may arise during cloud registration and processing (Ogawa and Hori, 2019).

In the scanning program of the Capris di Ciglie Palace, the same sequence that originated the design of the distribution plan of the atrium has been maintained: starting with a first scanning in the street, the second station is placed under the first vault of the entrance corridor through the access door to the interior. This first space only required one scanning station, given the reduced space and the simplicity of the two vaults that compose it. The first two scans formed a grouping to facilitate the union between the exterior and the interior. The following scans were made on each side of the central vault of the main reception space to avoid the blind spots generated by the twin axial arches. Together with a scan in the courtyard to determine the thickness of the façade walls, they formed the second grouping. Finally, the attached outbuildings were scanned, locating four stations, and forming the third grouping (Fig. 5).

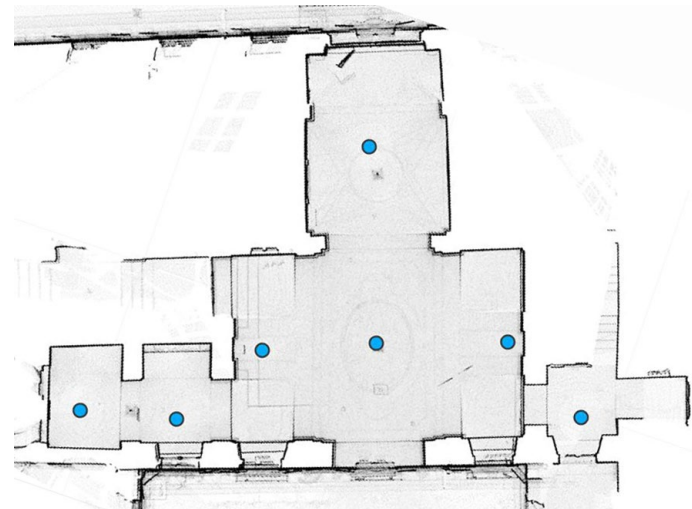

Figure 5. Positioning of the scanning stations inside the atrium of the Capris di Cigliè Palace. To these scans must be added those carried out in the street and in the courtyard. (processing by C. López González)

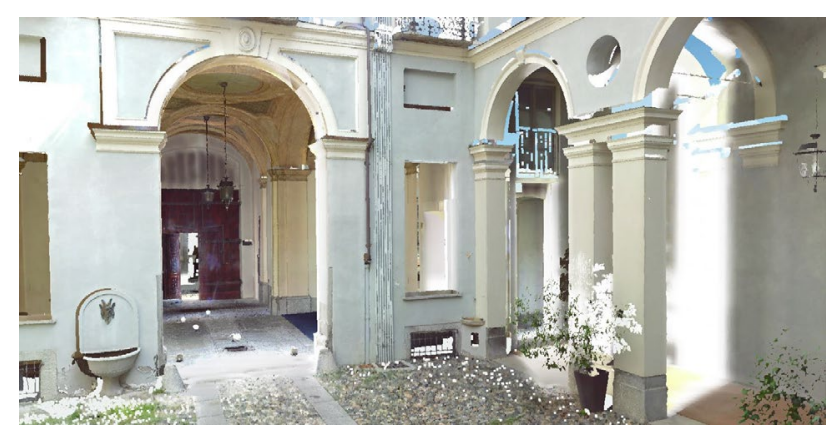

Figure 6. Location of referential spheres in the main reception space. Image extracted from the point cloud

(processing by C. López González).

With these programming conditions, a 48.9 mutual overlap was achieved, more than enough overlap to ensure efficient registration. Reference spheres were used to facilitate the subsequent joining of the point clouds. Their location was programmed so that three spheres were spotted from three consecutive stations (Fig. 6).

It is recommended that there be three reference points visible from different scans (Hajian et al., 2010). Finally, 9 scans were performed divided into three clusters. The maximum error of a point was $2 \mathrm{~mm}$ and the average error was $1.6 \mathrm{~mm}$. These data attest to the accuracy of the registration and, together with the $100,115,791$ points of the final cloud, confirm the fidelity of the result to the real construction.

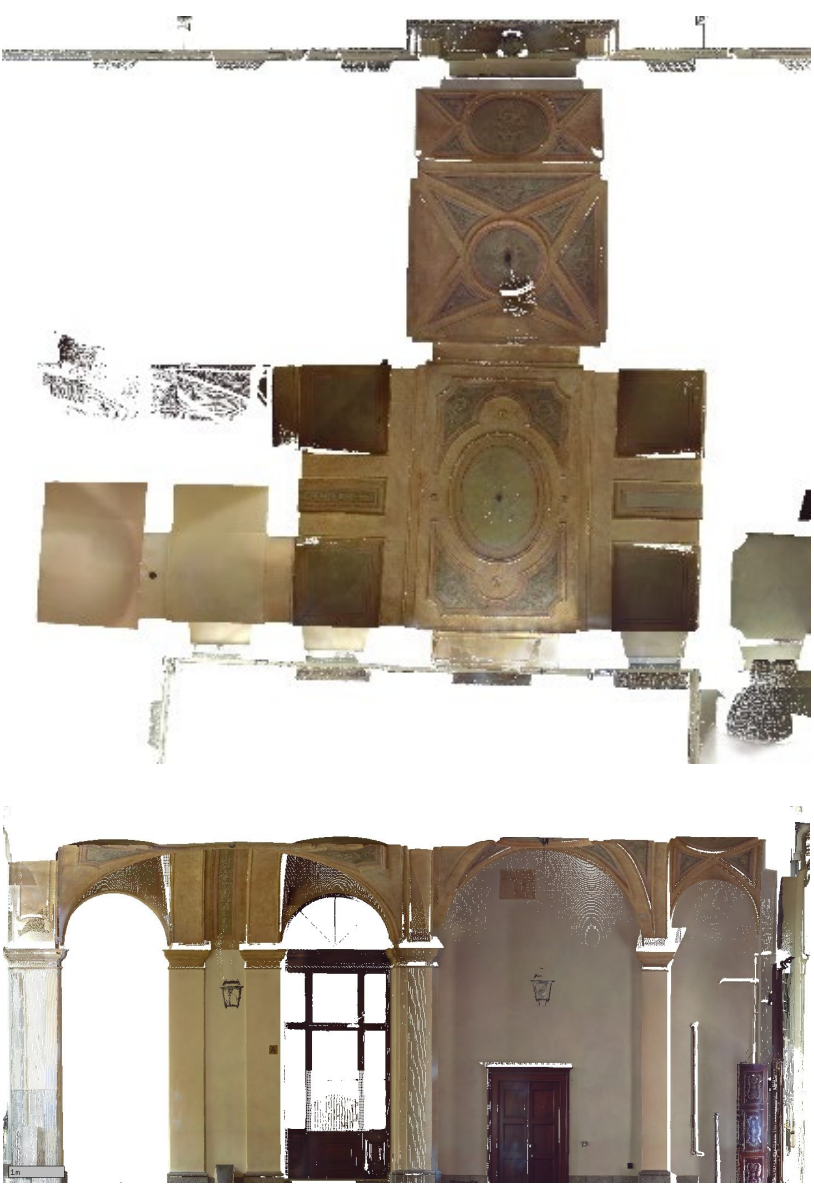

Figure 7. Horizontal and vertical sections extracted from the point cloud using Clipping box command (processing by C. López González). 
From the data obtained with the point cloud it has been possible to digitize the reconstruction of the vaulted system. For the registration and manipulation of the point clouds we used the Scene '19 program, associated with the Faro brand. Using the 'clippingbox' it is possible to make sections along the characteristic planes of the vault (Fig. 7). The digitalization of these orthophotos results in the graphic representation of the real sections that can be later compared with the original (ideal) design sections in order to quantitatively evaluate the differences between the design idea and the built architecture.

\section{PARAMETRIC MODELING FOR THE STUDY OF BUILT HERITAGE}

The purpose of this work is analytical and aims to study the relationships between the objects that make up the studied vaulted system and to define their intersections.

The work involved the following workflow:

- $\quad$ export of the point cloud obtained during the survey from Faro Scene $($ in.$e 57$ format;

- importing into Rhinoceros $(\subset$ and constructing vertical section planes perpendicular to the impost plane to extract planar geometries of 'dependent' and 'independent' arches;

- generation of curves using two geometric construction methods (elliptical and polycentric);

- generation of a parametric geometrical model using Grasshopper(C) algorithmic modelling tool;

- compare the interpretative model with the model obtained from the survey.

\subsection{Geometric approach for the critical reading and} interpretation of built architecture

In order to evaluate the conformation and the geometric construction of the vault, the perimeter of the base plane was determined from the point cloud and eight characteristic sections were extracted, which were useful for studying the curves of the arches (Fig. 8).

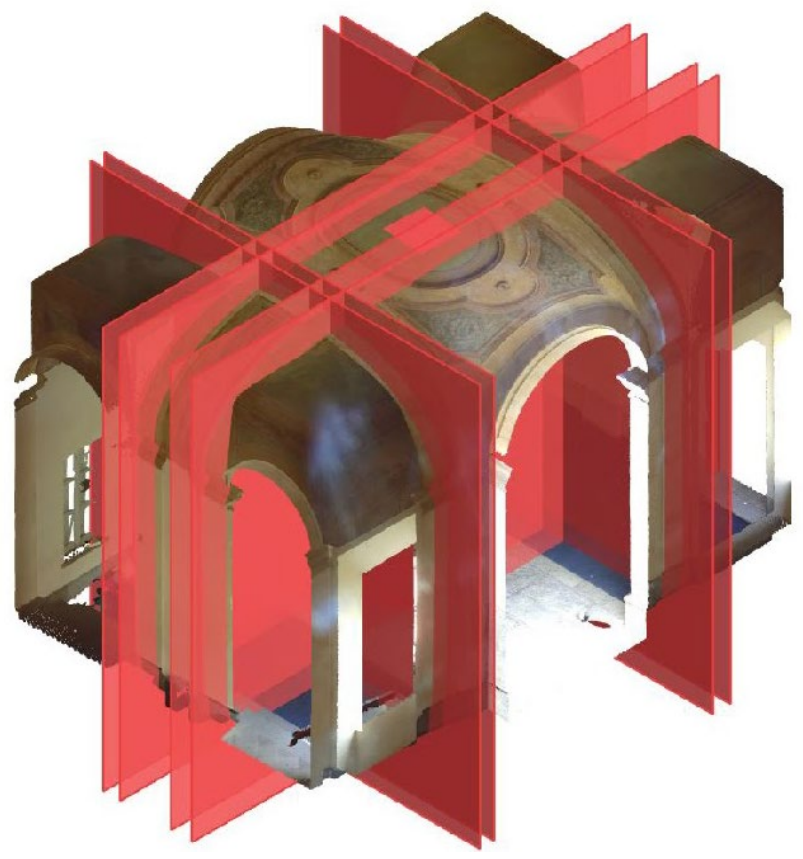

Figure 8. Section plans on point cloud (Processing: F. Natta).
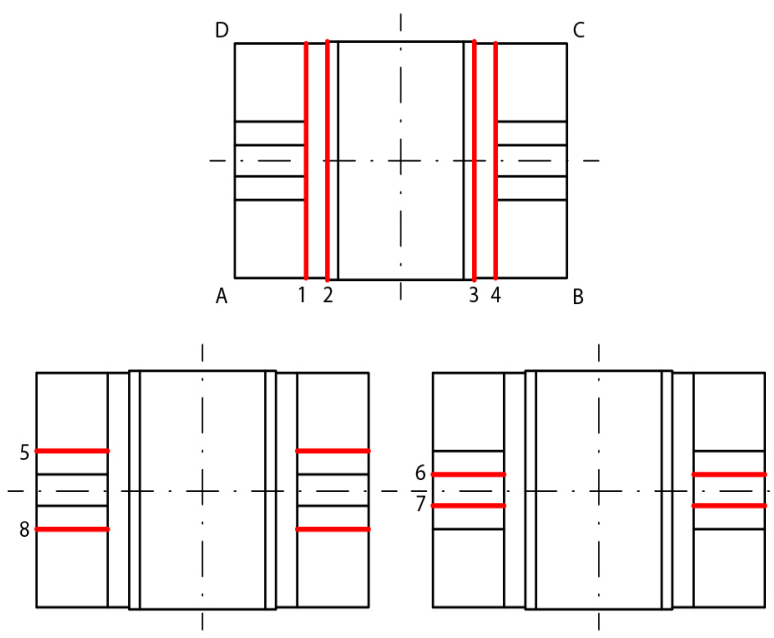

Figure 9. Position of section planes (Processing: F. Natta).

The section planes, vertical and perpendicular to the impost plane, were positioned in correspondence to the main, independent arches (coupled sections 1, 2, 3, 4) and the secondary, dependent arches (single sections 5, 6, 7, 8) constrained to the main arches (Fig. 9) (López González et al., 2020).

Following the identification of the sections, 2D polylines were extracted from the point cloud and inserted into Grasshopper(C) as a 'curve' object. We then proceeded to determine the geometric shapes that best conformed to the curves: in particular, two methods of geometric construction were compared, polycentric and elliptical (Samper et al., 2017; Lanzara et al., 2019).

For the polycentric curve, the constraints were constructed in Grasshopper(C) from the span and arrow of the arch. The first circumference is defined close to the impost plane with parameterized radius on which the point of change of curvature is identified by geometrical construction; the same point mirrored from the origin allows us to define, together with the point in key, an arc passing through three points and thus construct our polycentric curve (Fig. 10).
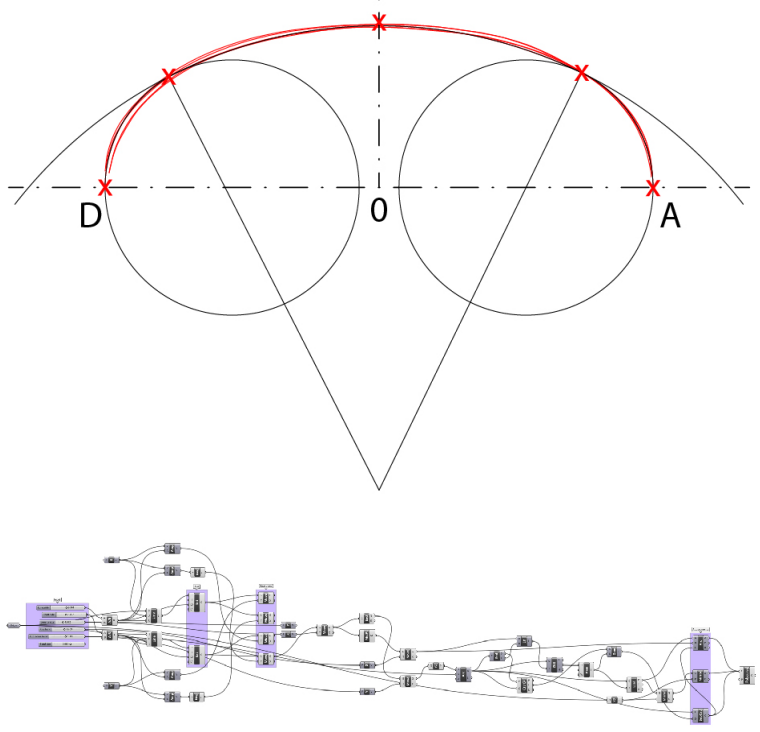

Figure 10. Visual scripting best fit arches: polycentric curve (Processing: F. Natta). 

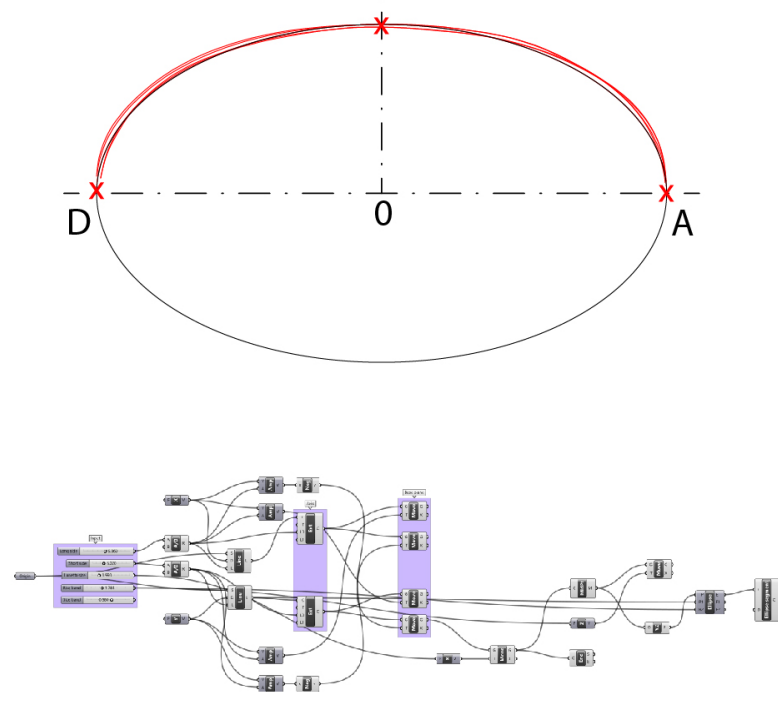

Figure 11. Visual scripting best fit arches: elliptic curve (Processing: F. Natta).

For the elliptical curve, only the light and arrow data are needed in Grasshopper to construct the ellipse. The programme automatically defines the entire curve on which we have to act by using "domain" to portion the part of the curve concerned (Fig. 11).

Once the geometric construction of these two examples had been completed, the distance between the real section and the curves obtained by the two construction methods was evaluated by means of a perpendicular line in order to find the curve closest to the one measured. What was obtained were minimum, average and maximum distance values (Tab. 1).

The table shows the comparison between the two curve construction methods and the curves that best fit the real one, and the values obtained led to the choice of the polycentric solution, on which the remaining operations were carried out.

\begin{tabular}{|c|c|c|}
\hline Distance & Elliptic curve & Polycentric curve \\
\hline $\min (m)$. & 0,000004 & 0,000027 \\
\hline $\operatorname{med}(m)$. & 0,030711 & 0,021958 \\
$\max (m)$. & 0,074273 & 0,061676 \\
\hline
\end{tabular}

Table 1. Distance between point cloud section and geometric curve.

\subsection{Ideal model of the bands and parameterization}

The approach used for the analysis of the main bands is also applied to the 'dependent' bands.

For this type of work, which is purely geometric, it is advisable to be clear from the outset about the aims and problems associated with it, in order to distinguish them from issues that would require an interdisciplinary comparison. The parametric model generated is intended to be a tool that allows a "quick" comparison between the architectures studied and the geometric simulations reproduced. A parametric model obtained from the survey data with greater precision would increase the complexity of the algorithm; adding up the geometriccompositional aspects of the surfaces, the plan irregularities and the accidentalities of the construction would go against the very purpose of the work.

Making this algorithm easy to use is a fundamental part of this study, in order to make it applicable to further comparable examples.

On the basis of these observations, it was deemed necessary to limit the number of parameters, constrained by an origin positioned on the central point at the level of the impost plane of the vault under analysis:

- $\quad$ long side length;

- $\quad$ short side length;

- $\quad$ size(s) of angular curved field(s) (1 or 2 given depending on whether it is square or rectangular);

- main curve rise;

- $\quad$ outer radius of main curve (polycentric curve only);

- $\quad$ outer radius of secondary curve (polycentric curve only);

- band width dimension.

These parameters make it possible to construct, by using an algorithm (Fig. 12), the component of the band vaults under study and to allow, as the data changes, the evaluation of different geometric configurations and the relative preliminary errors by comparing the curves generated by the section of the point cloud and the curves geometrically reproduced.

The conformation of this space allows, once the origin has been established, a division using the main axes and consequently generating curves and surfaces in only one of these quadrants in order to mirror the results obtained from the origin.

The main curve obtained from the result shown in the previous paragraph is positioned to allow the first division of the theoretical grid of this surface. Constraints are then created (position, tangency, etc.) to which subsequent geometries must refer.

The secondary curves, which are constrained to the main curve, follow the same algorithms for creating the geometry on which they are dependent (in this case a polycentric curve). The two curves that define the course of the secondary (dependent) arcs have different arrows, defined by the main curve and the size of

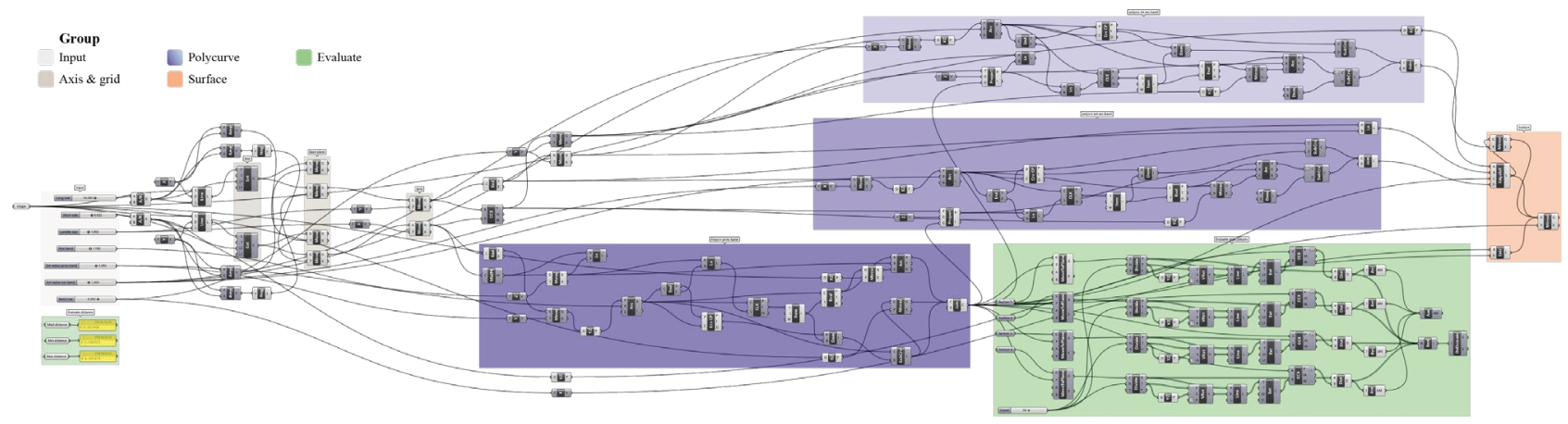

Figure 12. Canvas view of independent arches realized with Grasshopper (Processing: F. Natta). 
the secondary bands; the same radius of curvature is set for the first curve of the polycentric (near the set plane), imagining the recovery of portions of centering during the construction phases.

Through the definition of these three curves, it is therefore possible to generate the intrados surfaces of the bands: the main band is defined with a simple linear extrusion of the generating curve at a known distance; the secondary band is instead obtained by surfacing four edges (the two parameterized curves, the segment on the impost level and the portion of the curve of the main band). Based on the properties of symmetry and specularity of the bands, all the arcs of the vaulted system are constructed, highlighting the points that control the geometric conformation of the band system (Fig. 13).

This process (under development) therefore allows us to generate the curves and surfaces that best fit the data obtained from the survey. The algorithms developed on Grasshopper and the results obtained from it are easily replicated (e.g. Autodesk Dynamo) and can be exported to other software using different modelling and information methods (CAD, BIM).

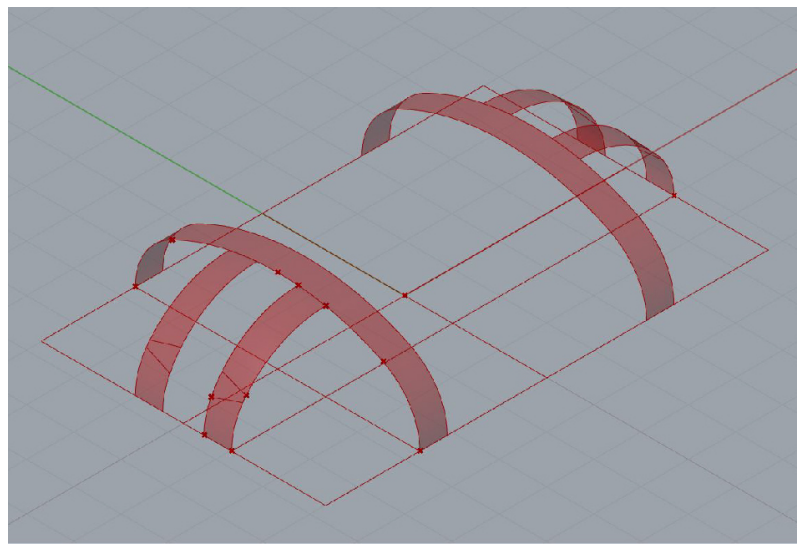

Figure 13. 3D model view of independent arches realized in Grasshopper (Processing: F. Natta).

\section{COMPARISON BETWEEN GEOMETRIC MODEL AND SURVEY DATA}

Any consideration one wishes to make in terms of comparing an ideal geometric model with the data obtained from a survey (in this case TLS) must take into account the inevitable propagation of errors from the first data subject to simplification and/or interpretation.

In the preceding paragraphs, the intention of this study on the analysis of the geometric-compositional component of complex vaulted surfaces has been clearly stated, and it is recalled here.

Evaluating and parameterizing every irregularity in the plan, lowering of the surfaces due to structural settlements or subsidence, adjustment of any inaccuracies and any decorations or stucco levelling would have added a complexity that could not (yet) be controlled. The point cloud data itself brings with it a series of errors, but given the intentions of our work, these are not the subject of further study here.

In any case, the components subject to error propagation throughout the process of creating the ideal model are known, which - when necessary for a geometric evaluation of the data are made explicit in the proposed workflow (Tab. 1).

This first order of evaluation on the characteristic curves of the arches, performed within the same software to accompany the digital reproduction phase, was then followed, in the final phase, by a comparison between the mesh model of the bands and the point cloud within the open-source software CloudCompare.
In CloudCompare, the mesh model exported in .obj format and the point cloud exported by Faro Scene $\subset$ in.$e 57$ format were superimposed (Fig. 14).

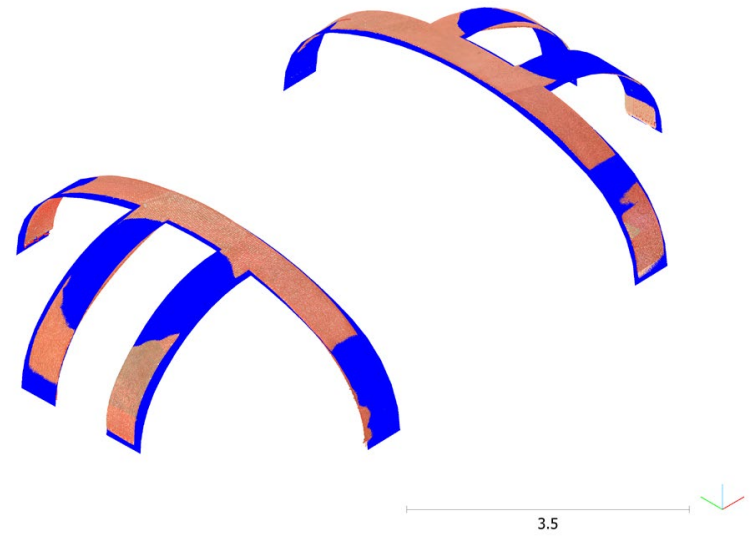

Figure 14. 3D model view of independent arches realized in Grasshopper (Processing: F. Natta).
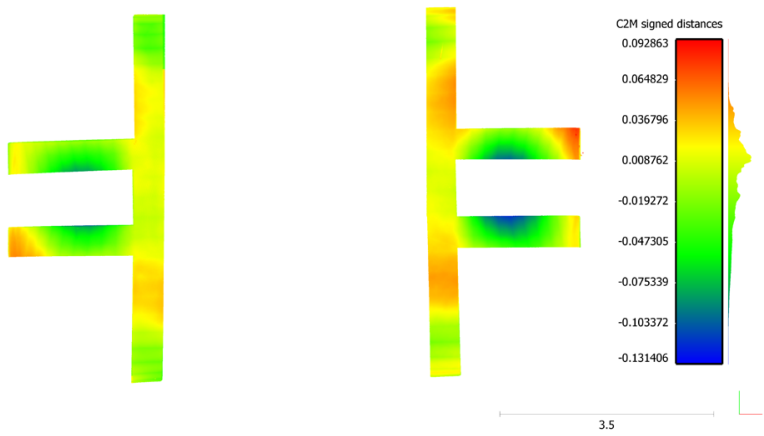

Figure 15. 3D model view of independent arches realized in Grasshopper (Processing: F. Natta).

The assumptions that the two digital products do not maintain a perfect correspondence have been made widely known; the constraints of orthogonality that accompanied this study are well evident from a comparison of the digital models of the main bands. These, made with tracking irregularities and constructional inaccuracies, added to a selection of smaller area in order not to include the decorative parts of the structure, lead to maximum deviations on the order of $\pm 0.12 \mathrm{~cm}$ and a modal value of \pm 0.012 (Fig. 15). These data are strongly influenced by the constraints and parameters assigned, especially in the last components created (see geometry of the secondary bands).

\section{CONCLUSIONS}

This study represents an approach to the geometric interpretation of complex vaulted systems and is part of a line of research in which the authors have been engaged for some years in the study and understanding of the relationships that exist between ideal design schemes, construction, architectural survey and geometric interpretation of complex vaults.

The studies and publications of the group aim at defining, by successive steps, a work methodology that defines a workflow applicable, apart from some necessary customisations, to a large number of case studies.

The complex vaulted systems studied, ranging from Planterian and star-shaped vaults to banded vaults and completely original examples which escape categorisation, were the field in which 
to experiment and refine the work method from time to time, constantly inserting useful tools into the workflow to compare ideal models, the result of geometric interpretation, with constructed buildings, such as the study of the main treatise sources, the structuring of standardised interpretative models in the construction logics, parametric modelling, and the superimposition of survey data on interpretative models.

This work is not yet intended to be a validation of the entire workflow, although it does present, through the parameterization of the surface generating curves, an interesting tool of comparison and study. In particular, the parameterization of the curves through ellipses or polycentric curves (with three centres) allows the verification of the textual sources: the polycentric arches, which in the analysis phase proved to be more adherent to the section curves obtained from the point cloud, confirm Curioni's indications on the realization of the centrings, in total agreement with the building site practices.

The next stages of the work will be oriented towards the systematisation of the survey method, which sees the threedimensional laser scanner survey as one of the fundamental steps and will aim to integrate into the workflow surveys aimed at understanding the material of the construction, such as thermography.

This paper is the result of the research on banded vaulted systems carried out together by the authors. The authors wrote together paragraphs 1 and 6, M. Vitali wrote paragraph 2, M. C. López González paragraph 3, G. Bertola paragraph 4, F. Natta paragraph 5.

\section{REFERENCES}

Almagro Gorbea, A., 2019. Half a century documenting the architectural heritage with photogrametry. EGE Revista de expresión gráfica en la edificación, 11, 4-30. https://doi.org/10.4995/ege.2019.12863

Auer Michael E., Ram Kalyan B. (editors), 2019. Cyber physical Systems and Digital Twins. Proceedings of the 16th International Conference on Remote Engineering and Virtual Instrumentation. Springer, Berlin. https://doi.org/10.1007/9783-030-23162-0

Chevalley, G., 1924. Elementi di tecnica dell'architettura: materiali da costruzione e grosse strutture. Pasta, Torino.

Curioni, G., 1866. Lavori generali di architettura civile, stradale ed idraulica e analisi dei loro prezzi. Negro, Torino.

Curioni, G., 1868. Geometria pratica applicata all'arte del costruttore. Negro, Torino.

Curioni, G., 1870. Costruzioni civili, stradali ed idrauliche. Negro, Torino.

Guarini, G., 1737. Architettura Civile. Gianfrancesco Mairasse, Torino.

Guarini, G., 1671. Euclides adauctus.... Zapatae bibliopolaea S.R.C, Torino.

Guarini, G., 1674. Modo di misurare le fabriche. Per gl'Heredi Gianelli, Torino.

Hajian, H. y Becerik-Gerber, B., 2010. Scan to BIM: Factor Affecting Operational and Computational Errors and Productivity Loss. 27th International Symposium on
Automation and Robotics in Construction. ISARC, Los Angeles. 265-272.

Lanzara, E., Samper, A., Herrera, B., 2019. POINT CLOUD SEGMENTATION AND FILTERING TO VERIFY THE GEOMETRIC GENESIS OF SIMPLE AND COMPOSED VAULTS. Int. Arch. Photogramm. Remote Sens. Spatial Inf. Sci., XLII-2/W15, 645-652. doi.org/10.5194/isprs-archivesXLII-2-W15-645-2019.

López González, M. C., Spallone, R., Vitali, M., Natta F., 2020. Baroque Banded Vaults: Surveying and Modeling. The Case Study of a Noble Palace in Turin. The International Archives Of The Photogrammetry, Remote Sensing And Spatial Information Sciences. Volume XLIII-B2, pp. 871-878. doi.org/10.5194/isprs-archives-XLIII-B2-2020-871-2020

Morena, S., Borja, A., Barrera, J.A., Barba, S., 2020. S-built graphic documentation of the monumento a la tolerancia. validation of low-cost survey techniques. EGE Revista de Expresion Gráfica en la Edificación, 13. https://doi.org/10.4995/ege.2020.14766

Ogawa, T., Hori, Y., 2019. Comparison with accuracy of terrestrial laser scanner by using point cloud aligned with shape matching and best fitting methods. The International Archives of the Photogrammetry, Remote Sensing and Spatial Information Sciences, Volume XLII-2/W9, pp. 535-541 8th Intl. Workshop 3D-ARCH "3D Virtual Reconstruction and Visualization of Complex Architectures", 6-8 February 2019, Bergamo.

Stanco, F., Battiato, S., Gallo, G., 2017. Digital Imaging for Cultural Heritage Preservation: Analysis, Restoration, and Reconstruction of Ancient Artworks. CRC Press. https://doi.org/10.1201/b1 1049

Samper, A., González, G., Herrera, B., 2017. Determination of the geometric shape which best fits an architectural arch within each of the conical curve types and hyperbolic-cosine curve types: The case of Palau Güell by Antoni Gaudí. Journal of Cultural Heritage, Volume 25, 56-64. doi.org/10.1016/j.culher.2016.11.015.

Spallone, R., Vitali, M., 2017. Volte stellari e planteriane negli atri barocchi - Star-shaped and Planterian Vaults in Turin Baroque Atria. Aracne, Ariccia.

Vitali, M., 2017. 3D Parametric Models for 'Planterian' Vaults in Turin. Nexus Network Journal, 19:2(2017), pp. 301-321. DOI 10.1007/s00004-017-0335-y 